\title{
OHOLOMTES
}

Revista d'economia, empresa i societat

Dossier sobre economia col-laborativa (I)

Economies de plataforma i negocis collaboratius

Coordinador: Joan Torrent-Sellens

EDITORIAL

\section{L'economia col-laborativa com a palanca de progrés i sostenibilitat en temps de pandèmia}

\author{
Joan Torrent-Sellens \\ Estudis d'Economia i Empresa, Universitat Oberta de Catalunya (UOC)
}

Segurament, una de les principals lliçons de les crisis sanitària, econòmica, social i institucional vinculades, però no sempre del tot originades, amb la pandèmia de la COVID-19 (alguns investigadors ho anomenen sindèmies, 0 sigui pandèmies diferents però amb efectes comuns) és que no hi ha recuperació possible sense aprofundir en el procés de transformació digital i sense reorganitzar l'activitat econòmica per fer-la més sostenible. Els resultats de la investigació sobre els fonaments i les conseqüències de les crisis pandèmiques ja ens assenyalen uns primers elements importants i innovadors:

En primer lloc, que la dinàmica de destrucció o d'aturada de l'activitat econòmica o de llocs de treball per sectors d'activitat posa de relleu que aquells sectors que s'han mostrat més flexibles amb la instauració de pràctiques remotes o virtuals de treball, producció i atenció a la demanda són els que han patit menys els efectes negatius de la crisi.

En segon lloc, que la relació entre digitalització, creixement econòmic i treball no és ni homogènia ni lineal. Si relacionem la digitalització (preparació digital) i l'evolució de l'activitat econòmica (PIB), es pot inferir que la digitalització s'associa amb la crisi econòmica per les cues. Només en aquelles economies més o menys digitalment preparades, la digitalització actuaria com a complement accelerador o mitigador de la caiguda del PIB.

En tercer lloc, que la poca preparació dels agents econòmics, especialment de les empreses, per aprofundir en la transició digital i per instaurar sistemes que combinin flexiblement la presencialitat i la virtualitat, explica bona part de la duresa de les crisis actuals. I, aquesta «nova flexibilitat» només és possible per mitjà d'una elevada intensitat en la utilització de les tecnologies digitals. Així doncs, la transformació digital és la nova palanca del progrés en temps d'economies de pandèmia.

En quart lloc, que tot i estar disponibles, els usos de les tecnologies i els sistemes de la transformació digital, especialment les tecnologies de segona onada (com la robòtica/intel-ligència artificial/aprenentatge de les màquines, internet de les coses, control i gestió de dades massives i al núvol, fabricació additiva/3D, sistemes ciberfísics, realitat virtual, comerç i treball digital i remot, i plataformes collaboratives, entre d'altres) per part de les empreses, especialment les de menys dimensió, són relativament baixos o molt baixos, i amb una incidència encara molt dèbil sobre els seus resultats. 
I, en cinquè lloc, que les crisis pandèmiques també exigeixen una nova orientació a l'hora d'abordar els resultats de les organitzacions, en particular els empresarials. La sostenibilitat, entesa com el vector de resultats que alinea els objectius econòmics, socials i ambientals de les empreses, s'ha d'ampliar i també ha d'incorporar els resultats en termes de salut. Però, per fer efectiva la transició de resultats, perquè les empreses obtinguin recompenses per ser viables, socialment responsables, verdes i saludables, cal que mobilitzin tot un conjunt d'actius i de capacitats dinàmiques que estan molt vinculats amb una profunda reorganització de la manera de fer els negocis.

En aquest context, no és estrany que l'economia collaborativa vagi rebent una atenció creixent, com a manera vàlida per articular la recuperació econòmica i social en temps de pandèmia. És veritat que el fenomen de l'economia col-laborativa és anterior a les crisis pandèmiques, i que l'explosió de moltes de les seves manifestacions, com els intercanvis massius per mitjà de plataformes digitals d'igual a igual o el treball remot tasca-massiva, ja va fer trontollar les activitats econòmiques tradicionals, com l'hoteleria o el transport de viatgers, molt abans que el món bategués al ritme de cinc lletres i dos números: COVID-19. Però, també és veritat que les plataformes digitals representen una gran oportunitat per al món post-COVID-19. Les seves extraordinàries capacitats de connexió entre els agents econòmics i socials, les infinites possibilitats de recirculació de recursos i la «liquiditat» de rols entre els integrants de les xarxes fan de les plataformes digitals no solament un nou agent econòmic que redueix dràsticament els costos de transacció, sinó també una de les innovacions econòmiques i socials més importants dels últims anys.

Probablement, quan es revisioni el paper de les plataformes digitals en temps històric, se les compararà amb les fàbriques. És molt probable que les plataformes siguin per al segle xxl, el mateix que les fàbriques van representar per al segle xIx i bona part del xx. Però, a ningú se li escapa que la fàbrica, com la institució organitzadora bàsica de l'activitat econòmica industrial, va generar efectes i externalitats positives i negatives alhora. No va ser fins ben entrada la fase madura de la Segona Revolució Industrial, just després de la finalització de la Segona Guerra Mundial, que el contracte social que intercanviava seguretat laboral i salaris fixos per productivitat va ser implantat massivament al món occidental amb uns resultats inigualables: l'edat d'or del creixement. Tres dècades d'un creixement econòmic sostingut, i l'etapa de menys desigualtat de rendes i més progrés social de la història moderna. Aquest és, precisament, el repte que ens planteja avui el sorgiment de l'economia de les plataformes i dels negocis col-laboratius. La tecnologia d'utilitat general ja està disponible, de manera que els mecanismes d'innovació ja han començat a generar iniciatives emprenedores i fonts de creixement econòmic per tot arreu. Només estem al principi del fenomen col/laboratiu. Totes les activitats i tots els sectors econòmics, d'una manera o d'una altra, s'hi veuran abocats. Ara bé, els problemes en termes d'organització de mercats, desigualtats generades i polítiques públiques també són i seran nombrosos i de gran envergadura. El repte serà, doncs, articular un nou contracte social per a l'economia de plataforma del segle xxl.

Precisament, i amb l'objectiu d'explicar els fonaments i els efectes que les plataformes digitals generen sobre l'economia, el consum, l'empresa i el treball, hem organitzat el primer dels dos monogràfics sobre l'economia col-laborativa que des dels Estudis d'Economia i Empresa hem coordinat per a la nostra revista, Oikonomics. Aquest primer monogràfic, que hem titulat: Economies de plataforma i negocis col-laboratius, aporta sis articles, sis aproximacions, sobre la dimensió de mercat i de negoci de l'economia collaborativa, mentre que deixem per al segon monogràfic, que coordinarà el professor Lluís Garay, l'estudi de les dimensions més socials i alternatives.

El primer article del monogràfic és tot un regal. Myriam Ertz, professora de la Universitat de Quebec a Chicoutimi (Canadà), directora del laboratori sobre les noves formes de consum a la mateixa universitat, i una de les principals expertes mundials en economia i consum collaboratiu fa un recorregut sobre el concepte, la dinàmica i les noves tendències de la col-laboració. El títol de l'article: «El consum col·laboratiu: de paraula de moda a terme conceptual. Les tres cares de l'economia compartida" ja és tota una declaració d'intencions. És un article ideal per copsar la recent aproximació acadèmica al consum collaboratiu i per a l'avaluació d'algunes de les seves tendències de futur. A partir de l'aproximació inicial al consum col·laboratiu, com a sistema de circulació de recursos que basa la seva novetat en la capacitat dels iguals per obtenir i proveir, és a dir, en la dualitat de rols, l'article examina les diferents tipologies de col·laboració (pura, intermitent i pseudocol-laboració) i les utilitza per establir l'encaix de l'economia collaborativa (mutualització) dins de l'economia compartida (redistribució). 
D’acord amb aquesta nova aproximació al consum collaboratiu, més adequada a la realitat actual de les plataformes, l'autora ens planteja escenaris molt interessants sobre el futur dels proveïdors, les mateixes plataformes i els obtenidors.

Feta la revisió conceptual, els dos articles següents del monogràfic es dediquen a analitzar i classificar dos dels fonaments de l'economia col-laborativa: les plataformes digitals i els models col-laboratius de negoci. La idea d'ambdós articles ha estat revisar els conceptes, definir una metodologia i uns eixos de classificació, i aportar evidències de la validesa de la classificació. En el segon article del monogràfic: «Plataformes digitals: fonaments i una proposta de classificació", Agustí Canals, col-lega dels Estudis d'Economia i Empresa de la UOC i lan Hüslkamp, doctorand del programa en Societat de la Informació i el Coneixement de la UOC, aborden la revisió i classificació de les plataformes digitals. És d'especial menció la seva revisió del concepte, des de la idea inicial d'espai físic per construir o fer activitat, per exemple els mercats tradicionals, fins a la visió més actual de la plataforma digital, com a xarxa per a la connexió i organització d'intercanvis. Seguint aquesta aproximació, i mitjançant l'explosió de necessitats i possibilitats d'interacció que promou la digitalització, els autors analitzen el conjunt de dimensions que defineixen les plataformes digitals i les classifiquen en funció de tres característiques clau per copsar el seu impacte econòmic i social: 1) el grau de digitalització dels béns, serveis i recursos intercanviats; 2) el nivell d'obertura de la plataforma: accés, provisió, ús i distribució; i 3) els seus mecanismes de governança en la presa de decisions: imposats o col-laboratius.

En el tercer article del monogràfic, titulat: «Models col-laboratius de negoci a l'economia digital», els collegues María Teresa Ballestar i Jorge Sainz de la Universitat Rey Juan Carlos a Madrid analitzen i classifiquen els models col-laboratius de negoci. A diferència dels models de negoci més tradicionals, els autors assenyalen que, als models collaboratius, la principal font de generació de valor són els usuaris de les plataformes, de manera que es generen tot un conjunt d'economies de plataforma, com la realització d'intercanvis mixtos (amb contraprestació i gratuïts), la cerca de la redistribució i la valorització d'actius infrautilitzats, la combinació de motivacions individuals i prosocials de participació, o la rellevància de la confiança entre els agents en aquests mercats digitals de doble cara. Així doncs, el valor a les plataformes es generaria en funció de l'escalabilitat, la transparència i l'operabilitat dels intercanvis digitals. En uns primers moments aquests models de negoci estaven orientats a l'altruisme, però l'èxit de les plataformes de negoci i, en certa mesura extractives, ha afeblit els models més purament collaboratius. Tot i amb això, en determinats contextos i mercats, els models comunitaris d'economia collaborativa funcionen amb normalitat i segueixen tenint molt de futur.

Després d'aquest primer bloc de conceptualització i caracterització de l'economia col·laborativa, les plataformes i els models de negoci collaboratius, el monogràfic analitza amb profunditat tres experiències concretes d'economies de plataforma. En el quart article del monogràfic, Miguel Ángel Malo de la Universitat de Salamanca, un dels economistes del treball que millor ha analitzat la problemàtica del treball en plataformes, i Javier Sánchez-Santos de la Universitat d'Alcalá analitzen el treball remot efectuat per mitjà de les plataformes (crowdworking). L'article, titulat: “Ocupació i condicions de treball a les plataformes de microtasques», se centra a investigar la situació actual d'aquesta forma alternativa de treball, amb especial atenció a la dinàmica de les seves condicions de treball. Després d'una revisió en profunditat de les evidències empíriques disponibles, els autors obtenen algunes tendències rellevants. Primer, que la utilització de les plataformes digitals per al treball organitzat en forma de microtasques està creixent amb molta força durant els últims anys. Segon, que molt d'aquest creixement està vinculat amb la deslocalització (en general, a proveïdors de treball remot situats en països de rendes baixes) d'una part de les tasques que les empreses oferents (la majoria ubicades en països de renda alta) abans feien internament. L'objectiu estaria vinculat amb la reducció de costos laborals i prestacions socials. I, en tercer lloc, que plantegen un trade off molt interessant entre la pèrdua d'ingressos i benestar per part dels treballadors als països amb rendes altes, però alhora, millores d'ingressos i benestar als països de rendes baixes. Aquest nou tipus d'outsourcing que, en paraules dels autors, comporta una mena d'immigració sense mobilitat física, de telemigració, planteja tot un conjunt de reptes econòmics i socials que només poden ser abordats en un diàleg social internacional.

En el cinquè article del monogràfic, els col-legues dels Estudis d'Economia i Empresa de la UOC, Josep Lladós-Masllorens, Antoni Meseguer-Artola i Inma Rodríguez-Ardura aborden una nova problemàtica molt interessant: la determinació de preus en una de les plataformes més importants del món, Airbnb. Estudiar les 
estratègies de determinació de preus a les plataformes, especialment si es distingeix entre els proveïdors no professionals i colllaboratius, i els proveïdors professionals o comercials, té molt de sentit. Primer, perquè l'evidència al respecte és pràcticament inexistent i segon perquè les motivacions, els interessos i l'estructura d'ambdós collectius són clarament diferenciats i, com a tals, també haurien de tenir implicacions administratives o impositives diferenciades. Emprant la teoria de preus hedònics, la caracterització dels mercats digitals bilaterals i les dades de la plataforma a la ciutat de Barcelona, els autors obtenen que els atributs intrínsecs (interaccions entre els obtenidors de la plataforma) i extrínsecs (característiques de l'allotjament) de la proposta de valor són essencials en la determinació de l'estratègia de preus per part dels amfitrions de l'allotjament. Especialment interessant és la implicació que relaciona la formació de preus al mercat digital amb el que succeeix al mercat convencional de la mateixa àrea, de manera que els efectes de congestió o de gentrificació entre ambdós mercats es podrien acabar reforçant mútuament.

Finalment, al sisè i darrer capítol del monogràfic, Gemma Domènech-Costafreda, assessora en polítiques públiques i regulació de les TIC al Centre de Telecomunicacions i Tecnologies de la Informació (CTTI) de la Generalitat de Catalunya, ens planteja la utilització de l'economia col/laborativa en un nou context, el context energètic. L'article, titulat: «Emergència climàtica, nou model energètic i economia col-laborativa: cap a les comunitats ciutadanes d'energia?", posa de relleu que la colllaboració en plataformes és un molt bon instrument per al canvi de model energètic, des de les energies fòssils cap a les renovables, en el context de l'emergència climàtica que es va accelerant any rere any. L'objectiu d'una economia neutra amb el clima també es pot treballar per mitjà de la utilització de xarxes distribuïdes de compartició en l'aprovisionament i l'obtenció d'energia entre iguals. Un nou model energètic, que entronca clarament amb la idea amb què iniciàvem aquesta edició: la necessitat d'aprofundir en la transformació digital colllaborativa i, a més, fer-ho buscant un nou vector sostenible d'objectius a assolir: una economia viable, socialment responsable, neutra amb el clima i saludable.

No voldria acabar aquesta breu ressenya sense agrair molt sincerament als autors la seva participació en el monogràfic. Elaborar articles per a revistes amb objectius divulgatius no sol estar entre les prioritats de la comunitat científica, més acostumada i, perquè no dir-ho, incentivada, en l'elaboració d'articles en revistes científiques d'impacte. Conscient de la dificultat, també dels problemes afegits per la pandèmia, i actuant en nom de la revista Oikonomics, dels Estudis d'Economia i Empresa, i dels lectors del monogràfic: gràcies, moltíssimes gràcies collegues. Ha estat un plaer coordinar-vos i continuar aprenent al vostre costat. Tanmateix, tinc la sensació que els lectors us ho agrairan més que jo. No queda massa bé que jo ho escrigui ara i aquí, però diria que estem davant d'un excel/lent monogràfic sobre l'economia col-laborativa. N'hi ha molts de disponibles, però amb una orientació acadèmica i divulgativa combinada com aquest, i en llengua castellana i catalana, diria que cap més. Un gran exercici de compartició de coneixement. Bona lectura per a tothom.

Citació recomanada: TORRENT-SELLENS, Joan. Economies de plataforma i negocis col|laboratius. L'economia col·laborativa com a palanca de progrés i sostenibilitat en temps de pandèmia. Oikonomics [en línia]. Novembre 2020, n. 14, pp. 1-5. ISSN: 2339-9546. DOI: https://doi.org/10.7238/o.n14.2010 


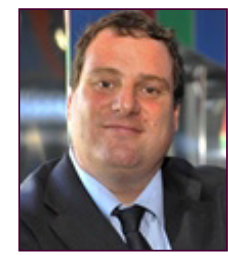

Joan Torrent-Sellens

jtorrent @uoc.edu

Estudis d'Economia i Empresa,

Universitat Oberta de Catalunya (UOC)

Catedràtic d'Economia dels Estudis d'Economia i Empresa de la Universitat Oberta de Catalunya (UOC). Director del grup d'investigació interdisciplinària sobre les TIC, i2TIC (http://i2TIC.research.uoc.edu). Especialista en l'anàlisi econòmica de la transformació digital i l'economia del coneixement, temàtica sobre la qual ha publicat 61 llibres i capítols de llibre, i 100 articles en revistes d'investigació indexades.

Els textos publicats en aquesta revista estan subjectes -llevat que s'indiqui el contrari- a una llicència de Reconeixement 4.0 Internacional de Creative Commons. Podeu copiar-los, distribuir-los, comunicar-los públicament i fer-ne obres derivades sempre que reconegueu els crèdits de les obres (autoria, nom de la revista, institució editora) de la manera especificada pels autors o per la revista. La llicència completa es pot consultar a https://creativecommons.org/licenses/by/4.0/deed.ca.

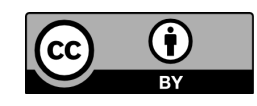

